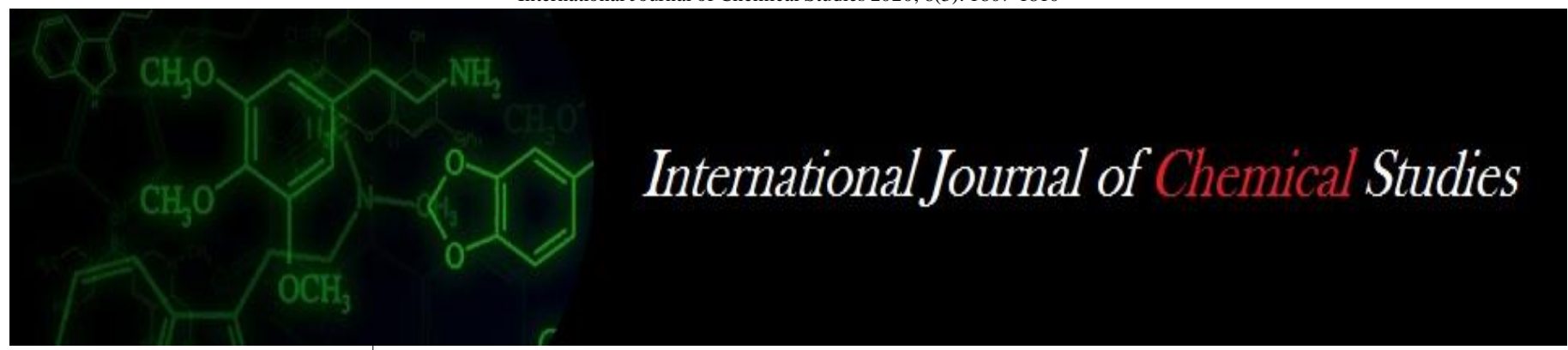

P-ISSN: 2349-8528

E-ISSN: 2321-4902

www.chemijournal.com

IJCS 2020; 8(3): 1807-1810

(C) 2020 IJCS

Received: 08-03-2020

Accepted: 10-04-2020

Rakesh Kumar Raman

Dairy Technology Division,

ICAR-National Dairy Research

Institute, Karnal, Haryana,

India

Swaminathan Santhalakshmy

Department of Food Science and

Technology, Pondicherry

University, Puducherry, India

Sowriappan John Don Bosco

Department of Food Science and

Technology, Pondicherry

University, Puducherry, India

Gaurav Kr Deshwal

Dairy Technology Division,

ICAR-National Dairy Research

Institute, Karnal, Haryana,

India
Corresponding Author: Rakesh Kumar Raman Dairy Technology Division, ICAR-National Dairy Research Institute, Karnal, Haryana, India

\section{Effect of encapsulating agents on antioxidative properties of spray dried jamun juice powder}

\author{
Rakesh Kumar Raman, Swaminathan Santhalakshmy, Sowriappan John \\ Don Bosco and Gaurav Kr Deshwal
}

DOI: https://doi.org/10.22271/chemi.2020.v8.i3y.9468

\begin{abstract}
The aim of the present work is to investigate the functional properties of Jamun fruit juice powder produced using three different carrier agents. Spray drying of the jamun juice powder was performed using a pilot scale spray dryer. Maltodextrin $21 \mathrm{DE}$, gum Arabic and a combination of both maltodextrin/gum Arabic was used as a carrier agents. Optimization of the carrier agents was initially done based on the product yield, Powder samples were analysed for its functional properties in terms of total carbohydrates, ascorbic acid and antioxidative activities to determine the best carrier agents retaining the functional properties of dried powder. The result reveals that the powder samples produced using gum arabic poses the best functional properties with limited physical properties whereas powder produced in combination with maltodextrin and gumarabic exhibiting the comparatively better functional as well as physical properties. Result obtained during the current investigation suggests the suitable carrier agents for production of jamun juice powder exhibiting its inherent functional attributes.
\end{abstract}

Keywords: Jamun fruit, spray drying, encapsulating agents, functional properties

\section{Introduction}

Jamun (Syzygium cumini) fruit popularly known as Indian blackberry is an underutilized fruit of Indian subcontinent and it belongs to Myrtaceae family. Jamun is of great significance among minor fruit of Indian origin, which is growing in various agro-climatic conditions (Aqil et al., 2012) ${ }^{[2]}$. This underutilized fruit is rich in phytoconstituents e.g. anthocyanins, flavonoids, steroids and phenolics etc. responsible for antioxidative properties (Banerjee et al., 2005; Baliga et al., 2011) ${ }^{[4,3]}$. Traditionally, it has been used in the Indian folklore medicine system because of availability of these phytochemicals (Patel and Rao, 2012) ${ }^{[13]}$.

Spray drying is one the widely and economical means of microencapsulation of thermal sensitive ingredients as core material receives lower heat which does not damage the components (Soottitantawat et al., 2003). Short residence time in combination with lower temperature confer spray drying operation suitable for heat sensitive food ingredients, like anthocyanins, as it promotes a higher flavor, color and nutrient retention (Masters, 1991). This method has been widely used because of many benefits as minimal flavor, nutrient, color loss or degradation due to instant contact with elevated temperature, more productivity and efficacious control of variables with high energy efficiency along with getting the products with diverse physical properties (size, shape and density) because of different processing conditions. Limitations for the production of fruit juice powder using spray drying are stickiness, hygroscopicity, and low solubility (Ferrari et al., 2012) ${ }^{[6]}$.

Various additives such as maltodextrin and gum arabic are used as drying adjunct to facilitate drying process as these carrier agents possess high solubility and low viscosity, an important consideration for spray drying operation (Quek et al., 2007) ${ }^{[14]}$. These carrier agents may safeguard the anthocyanins against unfavorable conditions like heat, light and oxygen, besides resulting in less hygroscopic powders (Tonon et al., 2010) ${ }^{[20]}$.

There is a lack of studies regarding the antioxidant activity of spray dried jamun fruit juice powder and have not been reported yet in literature. In this context, the present studies investigated the suitable carrier agents exhibiting the retention of best functional attributes without compromising the powder properties. 


\section{Materials and methods}

\subsection{Sample preparation and spray drying process}

Fresh jamun (Syzygium cumini) fruits were purchased from a local market of Puducherry, India. It was processed into juice immediately without any further storage. Maltodextrin 21DE, gum acacia (Himedia, Mumbai) and blend of both encapsulating agents $(25,15,15: 5 \%$ respectively) were added to the extracted juice as a carrier agent. The mixed solution was fed into a pilot-plant spray dryer.

Experiments were performed using a two- fluid nozzle pilotplant spray dryer at a drying rate of $0.6 \mathrm{~kg}$ of water $\mathrm{h}^{-1}$ under various combinations of operating parameters. This is followed by two cyclone separators. The first cyclone separator collects coarser particles and the second traps the fine and ultrafine particles. The feed flow rate was controlled through the speed of the peristaltic pump. For each spraydrying experiment, $100 \mathrm{ml}$ of feed was pumped over a wider period of time which varied depending on the feed flow rate. Feed flow rate was ranged from 10 to 16 RPM. Pressure was ranged from 0.4 to $1.6 \mathrm{~kg} / \mathrm{cm}^{2}$. The temperature of the feed mixture was maintained at $25^{\circ} \mathrm{C}$. Fig. 1 . shows the process flow chart for the development of jamun juice powder.

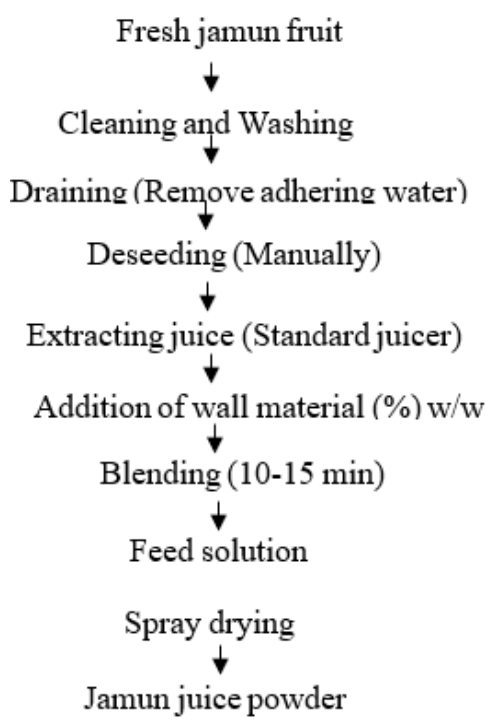

Fig 1: Process flow chart for the development of jamun juice powder

Dried powder samples were collected in the amber colored glass bottle at the base of the cyclone and stored in air-tight containers in a desiccator containing silica gel until further analysis. The produced samples were labeled as MD, GA and $\mathrm{C}$ for the carrier agent maltodextrin, gum arabic and the combination of both the materials used as encapsulation agents and analysed for its functional properties.

\subsection{Analytical methods}

\subsubsection{Total Carbohydrates}

Total carbohydrate $(\mathrm{CHO})$ content of the powder samples were evaluated using Anthrone reagent according to the method described in AOAC (2006) ${ }^{[1]}$. CHO content was analysed spectrophotometric ally and the absorbance was read at $630 \mathrm{~nm}$. Standard graph was used to calculate gram of $\mathrm{CHO}$ present in $100 \mathrm{~g}$ of sample against blank.

\subsubsection{Ascorbic acid}

Ascorbic acid content of the samples were determined by the method (Santana et al. 2013) ${ }^{[16]}$. 5g sample was blended with $6 \%$ metaphosphoric acid (HPO3) to make $50 \mathrm{ml}$ of the slurry and was diluted to $50 \mathrm{ml}$. The mixture was filtered. $2-5 \mathrm{ml}$ of the filtrate placed has to be taken in a $50 \mathrm{ml}$ separating funnel (A). The same amount of extractant (6\% HPO3) is taken in 2 or more separating funnels B \& C. Funnel B serves as the Dye Blank and funnel $\mathrm{C}$ serves as standard solution. Then another separating funnel D was taken, this D funnel serves as test samples. Test solution was separated and the color development was read at 500nm.

Ascorbic acid $=0.1 \times b-a / b-c$

Where, a - Sample value; b - Dye blank; c - Standard value.

\subsubsection{Total Antioxidant activity (DPPH radical scavenging activity) DPPH radical scavenging activity}

DPPH radical scavenging activity was estimated according to the method of Brand-Williams et al., (2005). The assay contained $2.9 \mathrm{~mL}$ of $0.1 \mathrm{mmol} \mathrm{L}^{-1} \mathrm{DPPH}$ in ethanol and $0.1 \mathrm{ml}$ of various concentrations of extracts and standards in the same solvent and was taken in a glass cuvette. The contents were mixed well immediately and the degree of reduction of absorbance was recorded for $30 \mathrm{~min}$ in an UVvisible spectrophotometer at 517nm (Shimadzu UV-2450). Optical densities at time zero (OD t0) and at 30min (OD t30) were used for calculating percentage radical scavenging activity. Percentage radical scavenging activity was plotted against the corresponding antioxidant substance concentration to obtain the IC50 (Inhibitory Concentration) value, which is defined as the amount of antioxidant material required to scavenge $50 \%$ of the free radicals in the assay system. $\mathrm{IC}_{50}$ values are inversely proportional to the antioxidant potency. DPPH\% Activity=Absorbance of Control-Absorbance of Standard*100/Absorbance of control

\section{Result and Discussion \\ 3.1 Functional Properties \\ 3.1.1 Total Carbohydrates}

Carbohydrates are extensively used as a encapsulating agent as it supports the food ingredients as wall material or carrier (Reineccius 1991) ${ }^{[15]}$. The ability of carbohydrates, such as starches, maltodextrin, corn syrup solids and acacia gums, to bind flavors is complemented by their diversity, low cost, and widespread use in foods and makes them the preferred choice for encapsulation (Mutka and Nelson,1988) ${ }^{[11]}$.

The most common carrier agents used in the spray drying of fruit pulps are maltodextrins and gum arabic, or a combination of both (Santhalakshmy et al., 2015) ${ }^{[17]}$ mainly due to their high solubility and low viscosity, which are important conditions for the spray-drying process (Quek et al., 2007) ${ }^{[14]}$. These carrier agents are preferred as encapsulating agent as it is reported to protect the fruit's bioactive compounds from oxidation. Total carbohydrate values of the spray dried powder samples are depicted in Table 1. Carbohydrate content of the spray dried powders samples are much higher $(34.41,33.71$ and $34.48 \mathrm{~g} / 100 \mathrm{gm})$ for $\mathrm{MD}, \mathrm{GA}$ and $\mathrm{C}$ respectively than fresh jamun juice $(5.10 \mathrm{~g} / 100 \mathrm{~g})$. No significant differences were observed between $\mathrm{MD}$ and $\mathrm{C}$. Higher the carbohydrate content in powder samples is resultant of their natural composition as maltodextrin added for encapsulation are purely carbohydrates whereas structurally GA comprised of polysaccharides, glycoproteins and their calcium, magnesium and potassium salts which is responsible for the comparatively lower $\mathrm{CHO}$ content in the GA samples (Flindt et al., 2005) ${ }^{[7]}$. Though, Sample $\mathrm{C}$ is of highest $\mathrm{CHO}$ content as it is mixture of both of them. 


\subsubsection{Ascorbic acid}

Role of ascorbic acid in human health is multidimensional as it supports healthy capillaries, gums, teeth and even helps to heal wounds, burns and broken tissues (Simon and Hudes 2000) ${ }^{[18]}$. Vitamin C content was estimated for spray dried powder samples to measure the antioxidative capacity. Table. 1. shows that there is significant difference between different carrier agents used. Jamun fruit juice is rich in ascorbic acid but sharp decline in the content can be observed as it is highly heat sensitive during thermal processing. Compare to jamun juice $(24.27 \mathrm{mg} / 100 \mathrm{gm})$ there is a significant difference in powder ascorbic acid content was found supporting the fact that thermal degradation of vitamin $\mathrm{C}$ during heat processing is a limiting factor for its availability in spray dried samples (Gregory et al., 2008) ${ }^{[8]}$. Within powder samples, vitamin C content was much lesser $(0.29 \mathrm{mg} / 100 \mathrm{~g})$ in powder $\mathrm{C}$, whereas gum Arabic shows highest $(0.80 \mathrm{mg} / 100 \mathrm{~g})$ among all, maltodextrin falls in middle with value $(0.67 \mathrm{mg} / 100 \mathrm{~g})$. Retention of ascorbic acid in gum Arabic samples may be due to synergistic effect of wall materials as well as GA composition.

Table 1

\begin{tabular}{|c|c|c|c|c|}
\hline Properties & JJ & MD & GA & C \\
\hline Total CHO(g/100g) & $5.10 \pm 2.880$ & $34.41 \pm 0.259^{\mathrm{a}}$ & $33.77 \pm 1.382^{\mathrm{b}}$ & $34.48 \pm 1.029^{\mathrm{a}}$ \\
\hline Ascorbic acid $(\mathrm{mg} / 100 \mathrm{~g})$ & $24.27 \pm 0.05$ & $0.67 \pm 0.05^{\mathrm{b}}$ & $0.8 \pm 0.03^{\mathrm{a}}$ & $0.29 \pm 0.04^{\mathrm{c}}$ \\
\hline DPPH radical scavening activity \% (IC $\mathrm{IC}_{50}$ Value) & 2.10 & 2.26 & 2.66 & 2.44 \\
\hline
\end{tabular}

\subsubsection{Total antioxidant activity}

\section{DPPH (2, 2-Diphenyl-1-Picrylhydrazyl) radical} scavenging assay

Antioxidants have gained much interest with respect to their protective effects against free radical damage involved in many degenerative diseases, including cancer. Both Jamun pulp and seed extracts were reported as an effective antioxidant compared with standard antioxidant compounds such as ascorbic acid and trolox (Aqil et al., 2012) ${ }^{[2]}$. DPPH radical scavenging assay were evaluated to determine the total antioxidative properties. In this study, the Inhibitory concentration of each sample at $50 \%$ (IC50) was used to compare their antioxidant capacity. Lower IC50 values mean that the required amount of a sample needed to reduce the initial DPPH concentration by $50 \%$ becomes lower, indicating a higher antioxidant capacity of the sample (Brand-Williams et al., 2005). The results of antioxidant activity are expressed in terms of percentage and are shown in fig. 2 . The antioxidant activity of GA was significantly higher than the MD and C.
The IC50 values of the Jamun juice and spray dried powder were 2.10, 2.26, 2.66 and 2.44 for MD, GA and C, indicating that about $90 \%$ of antioxidant capacity was retained after the drying process. The mechanism of action through which GA improves the antioxidant capacity may be due to the fact that GA contains several types of amino acid residues such as lysine, tyrosine, and histidine, whichare commonly considered as antioxidants biomolecules (Park et al., 2005) [12]. This suggests that powder samples might be promising potential antioxidants against DPPH radicals. These values are lower than that reported in Kumara et al., (2018) [9] reported for freeze dried jamun juice powder in which IC50 value were reported 4.7 determined spectrophotometry whereas quite high when determined using HPLC i.e.-10.5, while it is within the range of IC50 values of some fruits like grape skins, mulberries, mango, carambola, guava, and lichee as 1.10 to $9.60 \mathrm{mg}$ reported by Surinut et al., (2003) ${ }^{[19]}$ using $0.5 \mathrm{mM}$ DPPH.

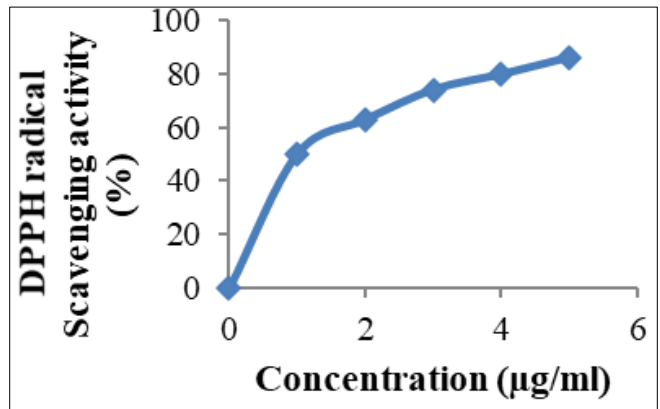

(a)

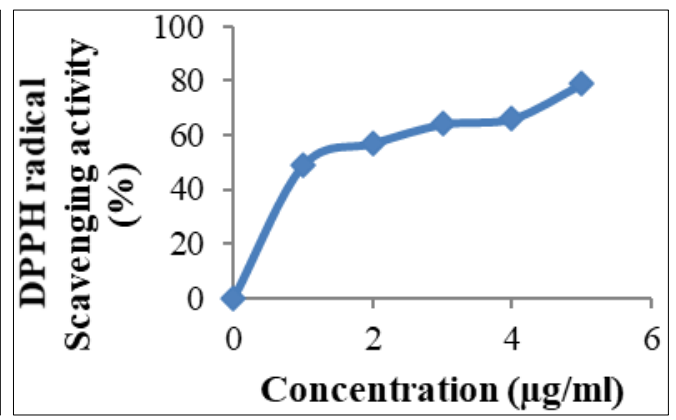

(b)

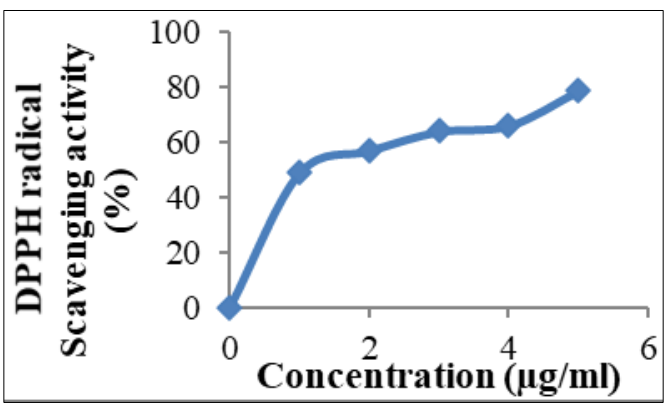

(c)

Fig 2: DPPH radical scavenging activity (IC 50 values) (a) MD (b) GA (c) C 


\subsection{Statistical interpretation of the data}

The experiments were carried out in triplicate and the data were analyzed statistically using SPSS software (SPSS PASW 20.0) and the means were separated using the Duncan's multiple range test $(\mathrm{p} \leq 0.05)$. All the data were presented as the means of triplicate determinations with the standard deviation.

\section{Conclusion}

Spray drying is an economical method for producing dry powders. It is not only a useful method of changing liquids into solids for increasing shelf-life and stability of colorant but reduced volume also helps in easy handling. Moreover, the short residence time and the use of lower temperatures make spray drying suitable for heat sensitive food components, such as anthocyanins found in jamun fruit. Results showed the significant difference in the functional properties including total carbohydrate, total ascorbic acid and DPPH radical scavenging activity

value $(p<0.05)$. Among three samples, sample produced with gumarabic gave good results for all the functional properties due to its inherent chemical compostion with limiting physical attributes. To improve, this combination of maltodextrin and gumarabic was used giving satisfactory result.

The results indicated that good quality powders with improved functional properties in terms of phytoconstituent can be produced by spray drying using Gum Acacia, which exhibits a huge potential for application of such bioactive powders in health management and in various food formulations.

\section{Acknowledgement}

The authors are thankful to University Grants Commission, New Delhi, India for financial support and Pondicherry University, Puducherry, India for facility provided.

\section{References}

1. AOAC, Official Methods of Analysis of the Association of Official Analytical Chemists, 18th edn. Gaithersburg, MD: Association of Official Analytical Chemists. 2006; (AOAC) International.

2. Aqil F, Gupta A, Munagala R, Jeyabalan J, Kausar H, Sharma RJ, Singh IP, Gupta RC. Antioxidant and antiproliferative activities of anthocyanin/ellagitanninenriched extracts from Syzygium cumini L. (Jamun, the Indian Blackberry). Nutrition and Cancer. 2012; 64(3):428-38.

3. Baliga MS, Bhat HP, Baliga BR, Wilson R, Palatty PL. Phytochemistry, traditional uses and pharmacology of Eugenia jambolana Lam. (black plum): a review. Food Research International. 2011; 44(7):1776-89.

4. Banerjee A, Dasgupta N, De B. In vitro study of antioxidant activity of Syzygium cumini fruit. Food Chemistry. 2005; 90(4):727-33.

5. Brand-Williams W, Cuvelier ME, Berset CL. Use of a free radical method to evaluate antioxidant activity. LWT-Food science and Technology. 1995; 28(1):25-30.

6. Ferrari CC, Germer SP, Alvim ID, Vissotto FZ, de Aguirre JM. Influence of carrier agents on the physicochemical properties of blackberry powder produced by spray drying. International Journal of Food Science and Technology. 2012; 47(6):1237-45.

7. Flindt C, Al-Assaf S, Phillips GO, Williams PA. Studies on acacia exudate gums. Part V. Structural features of Acacia seyal. Food Hydrocolloids. 2005; 19(4):687-701.
8. Gregory JF. Vitamins. In S. Damodaran, K. L. Parkin, O. R. Fennema (Eds.), Food Chemistry. (Chap.) New York, NY: CRC Press. 2008; 7:438-522.

9. Kumara P, Sunil K, Arun Kumar B Determination of DPPH Free Radical Scavenging Activity by RP-HPLC, Rapid Sensitive Method for the Screening of Berry Fruit Juice Freeze Dried Extract. Natural Product Chemistry Research. 2018; 6:341.

10. Masters K. Spray drying handbook. Spray drying handbook. 1985.

11. Mutka JR, Nelson DB. Preparation of encapsulated flavors with high flavor level. Food Technology (Chicago). 1988; 42(4):154-157.

12. Park EY, Murakami H, Matsumura Y. Effects of the addition of amino acids and peptides on lipid oxidation in a powdery model system. Journal of Agricultural and Food Chemistry. 2005 ;53 (21):8334-41.

13. Patel PR, Rao TR. Antibacterial activity of underutilized fruits of Jamun (Syzygium cumini L. Skeels). International Journal of Current Pharmaceutical Research. 2012; 4:36-9.

14. Quek SY, Chok NK, Swedlund P. The physicochemical properties of spray-dried watermelon powders. Chemical Engineering and Processing: Process Intensification. 2007; 46(5):386-92.

15. Reineccius GA. Carbohydrates for flavor encapsulation. Food Technology.1991; 45(3):144-6.

16. Santana AA, Kurozawa LE, de Oliveira RA, Park KJ. Influence of process conditions on the physicochemical properties of pequi powder produced by spray drying. Drying Technology. 2013; 31(7):825-836.

17. Santhalakshmy S, Bosco SJ, Francis S, Sabeena M. Effect of inlet temperature on physicochemical properties of spray-dried jamun fruit juice powder. Powder Technology. 2015; 274:37-43.

18. Simon JA, Hudes ES. Serum ascorbic acid and gallbladder disease prevalence among US adults: The Third National Health and Nutrition Examination Survey (NHANES III). Archives of internal medicine. 2000; 160(7):931-6.

19. Surinut P, Kaewsutthi S, Surakarnkul R. Radical scavenging activity in fruit extracts. In III WOCMAP Congress on Medicinal and Aromatic Plants-Volume 5: Quality, Efficacy, Safety, Processing and Trade in Medicinal. 2003; 679: 201-203.

20. Tonon RV, Brabet C, Hubinger MD. Anthocyanin stability and antioxidant activity of spray-dried açai (Euterpe oleracea Mart.) juice produced with different carrier agents. Food Research International. 2010; 43(3):907-914. 